\title{
(1)tinerarius 20

\section{LIVROS DIDÁTICOS DE MATEMÁTICA: ANÁLISE DOS INSTRUMENTOS PEDAGÓGICOS AUXILIARES PARA A APRENDIZAGEM DE GEOMETRIA NÃO EUCLIDIANA}

\author{
Wanderley Pivatto Brum \\ ufsc2013@yahoo.com.br \\ Sani de Carvalho Rutz da Silva \\ sani@utfpr.edu.br \\ Universidade Tecnológica Federal do Paraná - UTFPR \\ Campus Ponta Grossa
}

\begin{abstract}
Resumo: Apresentamos os resultados de um estudo que objetivou analisar os instrumentos pedagógicos presentes em seis livros didáticos de Matemática, em relação ao conteúdo de Geometria não Euclidiana, utilizados por professores do ensino médio de uma escola pública, no ano de 2013, localizada na cidade de Florianópolis, Santa Catarina. $\mathrm{O}$ estudo de caráter qualitativo, buscou primeiramente verificar o número de capítulos destinados ao tema "Geometria não Euclidiana" e, posteriormente, foram analisadas a presença e frequência de instrumentos pedagógicos categorizados como: figuras, charges, história em quadrinhos, indicação de sites, leitura adicional, glossário e práticas. Os resultados mostraram que a maioria dos livros analisados apresentaram o instrumento figuras como o mais frequente, seguido por textos complementares para leitura adicional. Instrumentos como charge e indicação de sites foram encontrados em apenas um dos livros. Em geral, os livros analisados reproduzem ainda um modelo memorístico de ensino que não privilegia a contextualização e participação do estudante no processo de aprendizagem.
\end{abstract}

Palavras-chave: livros didáticos; geometria não euclidiana, instrumentos pedagógicos, aprendizagem.

\section{MATH TEACHING TEXTBOOKS: ANALYSIS OF PEDAGOGICAL AUXILIARY INSTRUMENTS FOR LEARNING GEOMETRY NON EUCLIDIAN}

\begin{abstract}
We present the results of a study that aimed to examine the pedagogical instruments present in six textbooks in mathematics, compared to non-Euclidean geometry content, used by high school teachers in a public school, in 2013, located in Florianópolis, Santa Catarina. The qualitative study, first sought to verify the number of chapters dedicated to the theme "non-Euclidean geometry" and subsequently analyzed the presence and frequency of pedagogical instruments categorized as: pictures, cartoons, comics, statement of sites, reading further, glossary and practices. The results showed that most of the books presented analyzed the instrument figures as the most
\end{abstract}




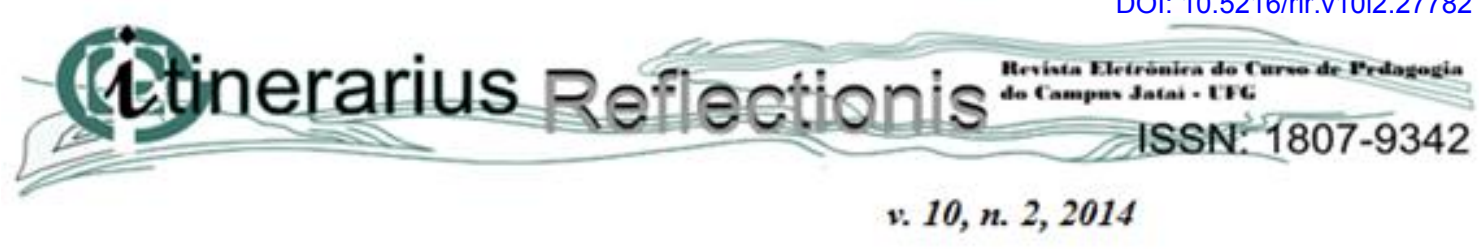

common, followed by additional text for further reading. Instruments such as charge and statement of sites were found in only one of the books. In general, the books also analyzed memorístico replicate a model of teaching that does not privilege the contextualization and student participation in the learning process.

Keywords: didactic textbooks, euclidean non-geometry, pedagogical instruments, learning.

Introdução

O guia de livros didáticos do Plano Nacional do Livro Didático (PNLD) do ano de 2008 traz dados relevantes para a utilização desse recurso didático em sala de aula, mostrando a importância de analisar um livro para que o professor possa utilizá-lo em sua prática docente. Ao abordar a importância do papel do professor na escolha do livro e na sua adequação à realidade da sala de aula, o guia enfatiza que:

É preciso observar, no entanto, que as possíveis funções que um livro didático pode exercer não se tornam realidade, caso não se leve em conta o contexto em que ele é utilizado. Noutras palavras, as funções acima referidas são histórica e socialmente situadas e, assim, sujeitas a limitações e contradições. Por isso, tanto na escolha quanto no uso do livro, o professor tem o papel indispensável de observar a adequação desse instrumento didático à sua prática pedagógica e ao seu aluno (BRASIL, 2007, p.12).

Ainda nesse sentido, o documento ressalta a importância do livro didático como recurso didático ao mesmo tempo em que enfatiza que este não deve ser a única fonte a ser utilizada pelo professor em sala de aula, e sim um dos meios para auxiliar no processo de ensino. Além disso, o guia enfatiza a importância de se complementar o livro didático, tanto no que diz respeito a ampliar suas informações e atividades e contornar deficiências, quanto adequá-lo à realidade do local onde ele será utilizado, considerando as especificidades do grupo de alunos envolvidos.

Desde 2006, através do Plano Nacional do Livro do Ensino Médio (BRASIL, 2007) o governo distribui livros de Matemática gratuitamente aos alunos matriculados na rede pública de ensino. O principal objetivo é proporcionar a todos os estudantes a 


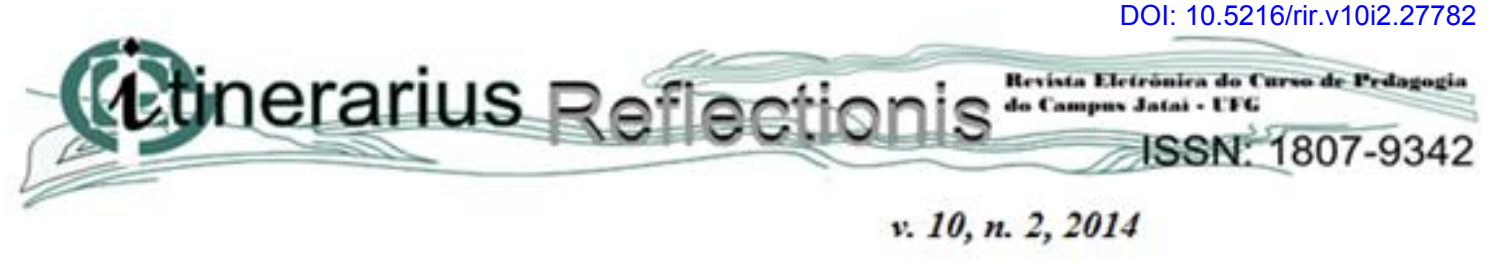

oportunidade de utilizar um material complementar, de qualidade, em sala de aula e fora dela. Segundo Bizzo (2000), a primeira avaliação oficial de livros didáticos realizada pelo PNLD ocorreu a partir de 1996. De acordo com Bittencourt (2004), vários livros até aquele momento, os mais vendidos aos governos estadual e federal, foram excluídos da lista dos aprovados quando erros graves conceituais foram apresentados à imprensa. Souto (2008) relata que na década de 1960, houve uma tendência a analisar os conteúdos dos livros didáticos privilegiando a denúncia do caráter ideológico dos textos. Entretanto, nos últimos anos há mudanças de abordagens, que integram reflexões de caráter epistemológico, essenciais para a compreensão da constituição das disciplinas e saberes escolares.

A partir de 1998, as editoras providenciaram as correções necessárias conforme critérios do programa, além de buscarem renovar seus livros didáticos com coleções novas e ainda com outros autores. Neste sentido, vários pesquisadores vêm se dedicando, há pelo menos duas décadas, a investigar a qualidade das coleções didáticas, verificando suas deficiências e apontando soluções para melhoria de sua qualidade. Pode-se citar, por exemplo, os trabalhos de Bongiovani (2010), Cabariti (2006), Vogelmann (2011), Vitrac (2006).

Sabe-se que a maioria dos livros didáticos ainda está em um formato de ensino baseado na memorização e em aula unilaterais (professor fala e aluno escuta), modelo denominado de bancário (FREIRE, 2010). Autores como Trivelato (2008), Vasconcelos e Souto (2008) consideram que a melhora nos livros didáticos precisa ser iniciada pela escolha dos conteúdos que devem atender à demanda da sociedade porque são objetos pedagógicos importantes que dão suporte na formação dos cidadãos. Desta forma, o livro didático passa a ser o ator principal no cenário de ensino/aprendizagem, algumas vezes, mais significativo que o próprio professor. Gambarini e Bastos (2006) citam que muitos professores utilizam o livro didático como a principal ou única fonte de textos utilizados em sala de aula.

Apesar da necessidade de utilização de outras metodologias e instrumentos de ensino, os livros didáticos provavelmente continuarão a exercer um papel determinante na maioria das escolas brasileiras. Assim, a análise dos livros didáticos torna-se 


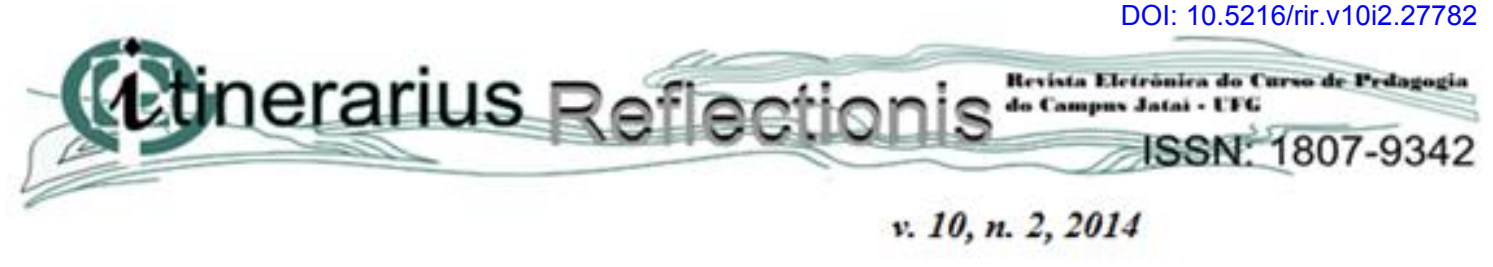

necessária para verificar se os conteúdos estão sendo trabalhados de forma correta, livres de concepções errôneas ou discriminatórias, e ainda, se trazem instrumentos para facilitar a aprendizagem por parte dos alunos, (SILVA, 2001), (TAMBARA, 2002), (VALENTE, 2003).

Diante desse panorama, o objetivo desse artigo foi apresentar os resultados da investigação desenvolvida a partir da análise de seis livros didáticos de Matemática, com relação ao tema Geometria não Euclidiana, utilizados por professores do ensino médio de uma escola pública, no ano de 2013, localizada na cidade de Florianópolis, Santa Catarina. O trabalho em sua sequência, apresenta aspectos teóricos sobre a importância do tema Geometria não Euclidiana, a metodologia da investigação, os resultados e análises, e por fim considerações de teor geral.

Um panorama do ensino de Geometria não Euclidiana

Tradicionalmente, os conhecimentos geométricos abordados em sala de aula se restringem as relações lógicas e construções de desenhos advindos de uma Geometria dedutiva e axiomática, estabelecida na Grécia, há cerca de 2700 anos e conhecida hoje como Geometria Euclidiana (CABARITI, 2006). No entanto, Cedrez (2012) relembra que ao observar a superfície terrestre, com sua forma elipsoidal, as montanhas, as ondas do mar e tantos outros objetos encontrados na natureza, evidenciam-se as dificuldades de construir alguns conceitos no campo da Geometria, sustentados por noções primitivas como de reta, ponto e plano.

Nas duas últimas décadas, houve uma intensa discussão nos meios educacionais, por parte dos membros de associações de profissionais da Matemática (KALLEFF, 2004), (CABARITI, 2006), (ALVES, 2008), (BONGIOVANI, 2010), (CARVALHO, 2011), (CEDREZ, 2012), (LEIVAS, 2012), (MARTOS, 2012) para a inclusão de conteúdos, advindos da Geometria Euclidiana, como a Geometria não Euclidiana nos bancos escolares, considerada como adequado à formação de estudantes para o século XXI, em decorrência dos avanços teóricos da Matemática e da Computação. Dessas discussões, emergiram alguns questionamentos: $\mathrm{O}$ ensino da Geometria não Euclidiana 


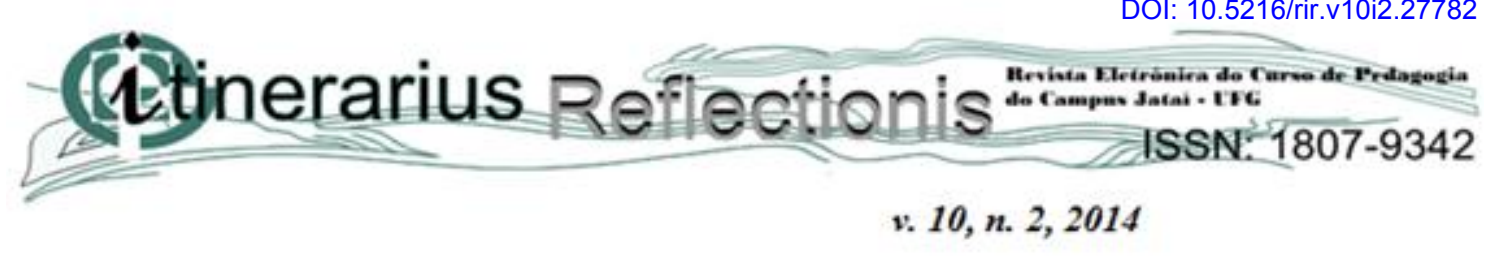

é um tema distante da realidade dos estudantes? O modelo geométrico para representar o planeta Terra abordado nas aulas de Geografia e Matemática é um plano, uma folha retangular ou uma superfície quase esférica? Se um dos pontos de discussão é a reformulação do ensino no Brasil, porque as Geometrias não Euclidianas ainda não são consideradas um ramo importante da Matemática por parte dos professores? Será que o ensino de Geometrias não Euclidianas vem causando inquietações em professores de Matemática, por ser um assunto novo e ainda desconhecido?

A busca de respostas para estas questões demonstra além de sua importância, a necessidade de divulgação junto aos professores desse conteúdo ainda pouco explorado em sala de aula, afinal, nos dias atuais, naves espaciais, por exemplo, percorrem em suas viagens, trajetórias que não são retilíneas e segundo (EVES, 2008; BOYER, 2009; (MLODINOW, 2010), existem registros que indicam o medo de alguns navegadores, por acreditarem que ao fim do horizonte, os navios eram engolidos ou chegaria ao "fim do mundo". Este pensamento era devido à interpretação que muitas pessoas atribuíam ao formato da Terra.

No ensino formal, é possível encontrar ainda, alguns estudantes que representam geometricamente o planeta por meio de um plano, e não é difícil comprovar tal afirmação, basta observar que, ao demonstrar o comportamento da gravidade sobre os seres humanos, evidenciam modelos euclidianos, em detrimento a modelos esféricos, hiperbólicos e até elipsóidicos. A Geometria é um dos temas mais interessantes para serem explorados pelos professores, por se constituir de uma riqueza em ilustrações, por possibilitar resoluções diversas com criatividade, e por fim, proporcionar aos estudantes, uma interação mais dinâmica com o conhecimento. Uma das justificativas para esta afirmação é a existência de discussões acerca da inserção de Geometria Esférica e Hiperbólica nos currículos escolares quem se encontram nos Parâmetros Curriculares Nacionais de Matemática (BRASIL, 1998), os quais apresentam a importância do ensino de outras geometrias, aos estudantes:

[...] a Matemática não evolui de forma linear e logicamente organizada. Desenvolve-se com movimentos de idas e vindas, com rupturas de paradigmas. Frequentemente um conhecimento é amplamente utilizado na ciência ou na tecnologia antes de ser incorporado a um dos sistemas lógicos 


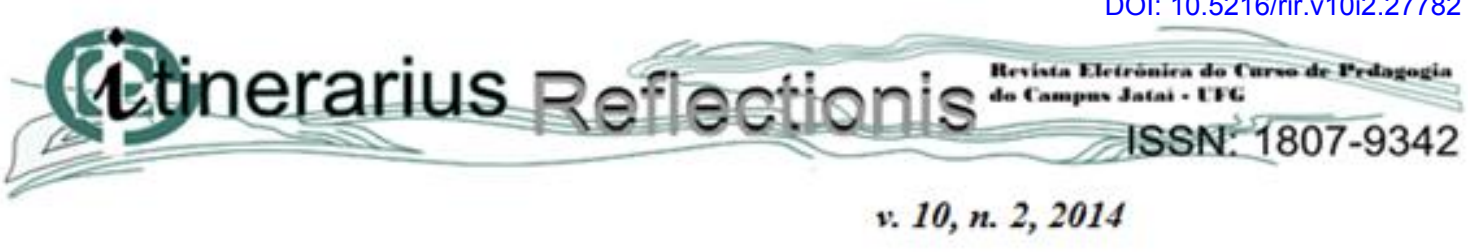

formais do corpo da Matemática. Exemplos desse fato podem ser encontrados no surgimento dos números negativos, irracionais e imaginários. Uma instância importante de mudança de paradigma ocorreu quando se superou a visão de uma única geometria do real, a Geometria Euclidiana, para aceitação de uma pluralidade de modelos geométricos, logicamente consistentes, que podem modelar a realidade do espaço físico. (BRASIL, 1998, p. 24, grifo nosso).

Neste sentido, os PCN (Parâmetros Curriculares Nacionais) colocam que, entre os objetivos do ensino de Matemática, se encontra o desenvolvimento do pensamento geométrico. Recomenda-se a exploração de situações de aprendizagem que levem o estudante a resolver situações problema de localização e deslocamento de pontos no espaço, ler mapas, estimar e comparar distâncias percorridas, reconhecer propriedades de formas geométricas e saber usar diferentes unidades de medida. Portanto, há uma orientação para situações de aprendizagem que levem o estudante a estabelecer diferenças entre objetos sob diferentes pontos de vista, construindo e interpretando suas representações.

Para estabelecer diferenças entre objetos geométricos conforme orienta os PCN, é preciso identificar uma pluralidade de modelos geométricos na natureza, que pode ser pelo estudo das navegações, no sistema de localização por GPS (Sistema de Posicionamento Global), em aulas de Geografia ao tratar sobre o planeta Terra, na Física para compreensão do comportamento da luz no espaço, em objetos comuns do nosso cotidiano, como trompetes, batatas empalhadas, cornetas, ondas do mar, poltronas, garrafas de vinhos e tanto outros que transitam nas diversas áreas do conhecimento. Com tantas possibilidades citadas e diversas pesquisas realizadas, porque grande parte dos currículos escolares se encontra ainda pautados em conhecimentos euclidianos?

Mesmo com certa dificuldade para os pesquisadores apresentarem respostas convincentes, o fato é que com relação a sua aplicação em sala de aula, o ensino de Geometria não Euclidiana há quase três décadas se manifesta em algumas propostas curriculares brasileiras, como por exemplo, no Currículo Básico da Prefeitura Municipal de Curitiba (1988) ou na Proposta Curricular para a Matemática do Ensino Fundamental de São Paulo (1991, p. 88) que sugere o ensino da Geometria não Euclidiana para “[...] concretizar as noções de círculos máximos e circunferências máximas, respectivamente, 


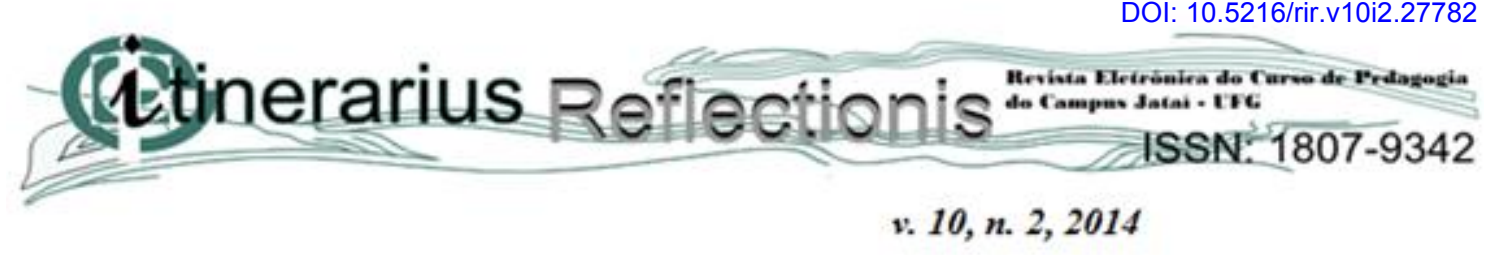

em esferas e superfícies esféricas [...]”. Contudo, discussões sobre o ensino de noções básicas de Geometria não Euclidiana ainda não aconteceu efetivamente nas escolas da rede pública do Estado de Santa Catarina, possivelmente justificado pela dificuldade de sua compreensão por parte dos professores, pelo desconhecimento de linhas metodológicas ou, ainda, pela ausência de textos nos livros didáticos que contemplem o assunto. Sob o olhar da aprendizagem de Geometria, os estudantes em geral têm acentuadas dificuldades em resolver problemas que transitam no campo dos conceitos geométricos. As fragilidades que os estudantes evidenciam na interpretação e solução de situações do cotidiano, nos quais são necessários conhecimentos geométricos, é uma dos grandes desafios enfrentados pelos professores.

\section{Procedimentos metodológicos}

Realizou-se, por meio de um estudo qualitativo, a análise de seis livros didáticos de Matemática utilizados pelos professores de Matemática de uma escola da rede pública localizada na cidade de Florianópolis, Santa Catarina, no ano de 2013. Os livros de ensino médio foram eram os que os professores no momento de sua prática docente utilizavam para apresentar o conteúdo a turma, no qual serão denominados L1 (livro 1), L2 (livro 2), L3 (livro 3), L4 (livro 4), L5 (livro 5), L6 (livro 6). Todos os livros analisados eram volume único. Primeiramente, verificou-se o número de capítulos relacionados à Geometria não Euclidiana, bem como o número e o tipo de instrumentos pedagógicos auxiliares presentes nestes capítulos. Os critérios para análise foram divididos em classes: figuras, atividades práticas, leitura adicional, indicação de sites, glossário, histórias em quadrinhos e charges. Os dados foram analisados levando-se em consideração a frequência dos instrumentos nos livros. 


\section{(1etinerarius Reflectionis:}

v. 10, n. 2,2014

\section{Resultados}

Todos os livros analisados apresentaram capítulos direcionados à Geometria não Euclidiana e instrumentos pedagógicos auxiliares para a explicação do tema (Quadro 1).

Quadro 1: Comparação no número de capítulos dedicados ao tema Geometria não Euclidiana e no número de instrumentos pedagógicos presentes nos seis livros analisados.

\begin{tabular}{|c|c|c|c|}
\hline $\begin{array}{c}\text { Identificação } \\
\text { do livro }\end{array}$ & $\begin{array}{c}\text { Número de } \\
\text { capítulos }\end{array}$ & Autores & $\begin{array}{c}\text { Total de Instrumentos } \\
\text { pedagógicos }\end{array}$ \\
\hline L1 & 4 & Dante, L.R. & 36 \\
\hline L2 & 2 & Giovanni, J.R.; Bonjorno, J. R. & 16 \\
\hline L3 & 3 & Filho, B.B.; Xavier, C. & 20 \\
\hline L4 & 2 & Iezzi, G.; Dolce, O.; Desenszajn, D.M. & 14 \\
\hline L5 & 2 & Giovanni, J.R. & 15 \\
\hline L6 & 2 & Benetti, B. & 13 \\
\hline
\end{tabular}

$\mathrm{O}$ instrumento pedagógico mais comum é a utilização de figuras, presentes em grande quantidade em todos os livros analisados. Textos para leituras adicionais também estão presentes nos seis obras. Cabariti (2006) afirma que alguns estudos e práticas docentes a partir do levantamento de alguns aspectos que destacam o interesse de uma proposta de aprofundamento da Geometria Euclidiana, cujos conceitos são objetos de ensino na Educação Básica, encontra-se relacionada com a riqueza da história da Geometria, no qual proporcionaria um estudo e uma reflexão acerca dos conhecimentos científicos no campo da Geometria não Euclidiana.

No entanto, Almouloud (2004) entende que a carência de alternativas no campo metodológico para os professores trabalharem em sala de aula o tema Geometria não Euclidiana, está relacionado diretamente com sua formação básica, precária e deficiente em Geometria. Salienta, ainda, que os cursos de formação inicial de professores, tanto os cursos de magistério como os de licenciatura, continuam não dando conta de discutir suficientemente com seus alunos, futuros professores, propostas mais eficientes para o ensino de Geometria, e, também as modalidades de formação continuada, postas em ação nos últimos anos, basicamente na forma de cursos de reciclagem, não têm atingido 


\section{(ctinerarius Reflectionis \\ ISSN: $1807-9342$}

\section{v. 10, n. 2,2014}

(MARTOS, 2002), ainda o objetivo de mudar a prática na sala de aula em relação ao ensino de Geometria.

Também tirinhas e indicação de sites educativos foram encontrados em apenas um livro cada. Nenhum livro utilizou charges como instrumento para ensino de Geometria não Euclidiana (Quadro 2). É importante ressaltar que o instrumento atividade prática, encontrado nos seis livros, foi o mesmo modelo (construção de retas em objetos não euclidianos).

Quadro 2. Frequência dos instrumentos pedagógicos em capítulos referentes ao tema Geometria não Euclidiana em seis livros de Matemática avaliados.

\begin{tabular}{|l|c|c|c|c|c|c|}
\hline $\begin{array}{l}\text { Instrumentos } \\
\text { pedagógicos }\end{array}$ & L1 & L2 & L3 & L4 & L5 & L6 \\
\hline Figuras & 27 & 10 & 12 & 10 & 10 & 9 \\
\hline Atividade prática & 1 & 1 & 1 & 1 & 1 & 1 \\
\hline Indicação de sites & 1 & 0 & 0 & 0 & 0 & 0 \\
\hline Tirinhas & 0 & 0 & 1 & 0 & 0 & 0 \\
\hline Charges & 0 & 0 & 0 & 0 & 0 & 0 \\
\hline Glossários & 1 & 1 & 1 & 1 & 1 & 1 \\
\hline Leitura adicional & 6 & 4 & 5 & 2 & 3 & 2 \\
\hline
\end{tabular}

Em geral, com relação aos livros analisados percebe-se que estão baseados ainda em um modelo tradicional de ensino, de forma fragmentada e não apresentando a interrelação entre conteúdos que precisam ser correlacionados, sendo estes colocados em capítulos separados, neste caso, a Geometria Euclidiana e a Geometria não Euclidiana. Os temas de Geometria não Euclidiana encontram compartimentalizados em capítulos (Visão geral da geometria não euclidiana, a queda do quinto postulado, os matemáticos do século XVI, etc.) e separados dos conteúdos de Geometria. Esta forma linear foi observada em todos os livros analisados. Dessa forma, temas como geodésicas e triângulo esférico não são citados nos capítulos de Geometria não Euclidiana. O aluno, desta forma, terá dificuldades de perceber a interrelação entre a geodésica e o triângulo esférico. Cabariti (2006) sugere que os modelos geométricos e suas propriedades devam 


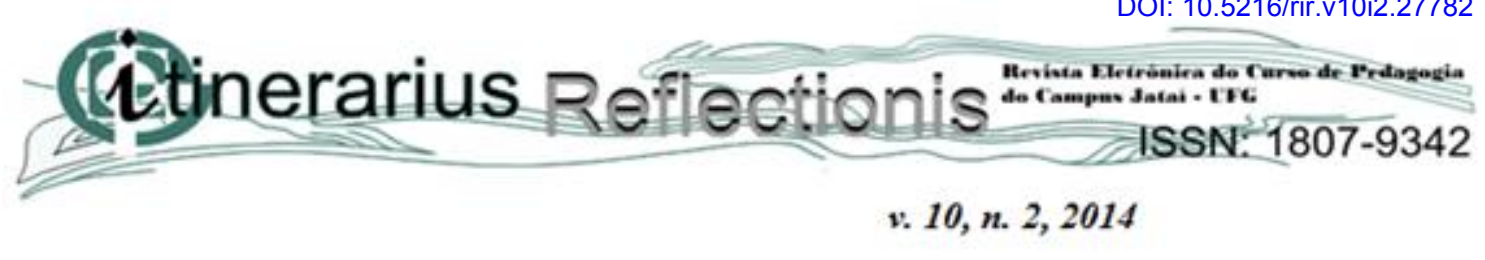

ser estudadas no momento que o tema geometria for apresentado ao aluno, pois são conteúdos correlacionados.

Constatamos também, que os exercícios de fixação estão divididos em questões objetivas (retiradas de concursos e vestibulares nacionais) e questões discursivas, estas, normalmente, não incentivam o aluno a buscar respostas em outros capítulos ou relacionar conteúdos e, até mesmo, disciplinas diferentes. Alves (2008) aponta que a diversidade dos exercícios que compõem o livro didático é necessária para que haja um crescimento gradual do nível de dificuldade para o aluno. Por outro lado, Barreto (2007) entende que as figuras são os atrativos principais nos capítulos, pois através delas os estudantes podem visualizar, com clareza, o que está sendo explicado no texto. As imagens apresentam boa qualidade, legendas explicativas e, quando necessário, setas para apontar algum detalhe mais específico. Entretanto, não constituem uma novidade em termos de instrumentos pedagógicos.

Quanto às atividades sugeridas pelos livros analisados, constatamos que apenas "a menor distância entre dois pontos”. Entretanto, várias atividades práticas simples, para o ensino de Geometria não Euclidiana, como a "saída a campo para identificação de objetos euclidianos e não euclidianos", "construção de objetos não euclidianos com material alternativos", "pintura em perspectiva de uma paisagem", entre outras, podem ser encontradas em dissertações de mestrado e doutorado (ver, por exemplo, BRUM, 2013) ou até mesmo em sites educacionais na internet (ver, por exemplo, http://www.portaldoprofessor.mec.gov.br). Jogos didáticos e outras atividades também são indicados em artigos publicados na revista BOLEMA, (Boletim de Educação Matemática) ou na revista Zetetiké (Revista de Educação Matemática).

As atividades práticas podem auxiliar na aprendizagem, proporcionar aulas diferentes, estimular os alunos e promover o gosto pela Matemática, em particular, a Geometria. Apesar disso, os livros didáticos analisados não incorporaram estas sugestões. Os livros didáticos na área de Matemática devem conter sugestões de atividades práticas claras, objetivas, com aplicabilidade, funcionalidade e roteiros de interpretação que estimulem o pensamento crítico do aluno. Nessa direção, Galliazzi et 


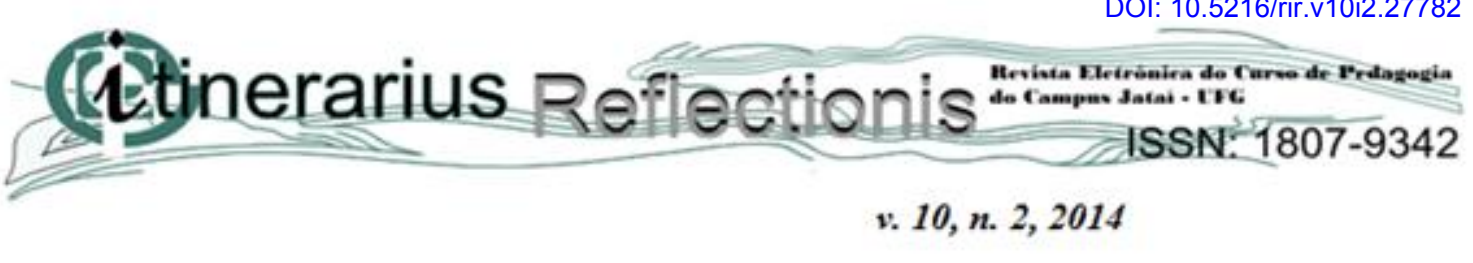

al. (2001) afirmam que é necessário que os professores superem o entendimento de que teoria e prática são duas entidades separadas, mas complementares.

A análise dos livros mostrou que L1 apresenta como instrumentos figuras, uma atividade prática e leituras adicionais (que auxiliam na aprendizagem) e mostra o conteúdo a ser estudado de outra forma, além de apresentar a indicação do uso da internet, universo presente na vida dos estudantes. A presença do glossário facilita para os alunos a compreensão dos termos. Da mesma forma, L2 teve como instrumento mais frequente as figuras. Não há a presença de instrumentos mais atuais como a indicação de sites e o uso de tirinhas (história em quadrinhos) e charges. Já L3 e L4 apresentaram textos adicionais inseridos dentro dos capítulos, e da mesma forma que nos outros livros, as figuras foram o instrumento mais presente.

De forma semelhante, L5, L6 e L7 apresentaram o mesmo esquema de organização, com a presença de diversas figuras representativas do texto e ausência de instrumentos pedagógicos mais atuais como a indicação de sites. De forma diferente, L6 apresenta como leitura adicional textos mais longos e com questões discursivas para serem respondidas, enquanto L7 contém, no decorrer do capítulo, pequenos textos relacionados ao tema.

Com relação à presença de leituras adicionais, percebeu-se que no L1 estes textos eram extraídos de notícias de jornais e revistas, trazendo temas atuais associados com o conteúdo, possibilitando ao aluno relacionar a matéria com algo presente no seu dia-adia. Já em L2 e L6, os textos são maiores e, em alguns momentos, apresentam questões para o aluno responder. Neste ponto, encontra-se um diferencial com relação aos outros livros, pois algumas respostas exigem que o aluno busque compreender outros conceitos presentes em capítulos diferentes e relacionar conteúdos.

Os livros L3, L4 e L7 apresentam textos pequenos que exemplificam o conteúdo que foi trabalhado. Para Struik (2010) e Vitrac (2006), as leituras complementares devem transpor o texto tradicional do livro didático, apresentando aos leitores uma abordagem mais atual e mais ampla com o objetivo de atrair a curiosidade do estudante, contextualizando o conteúdo. 


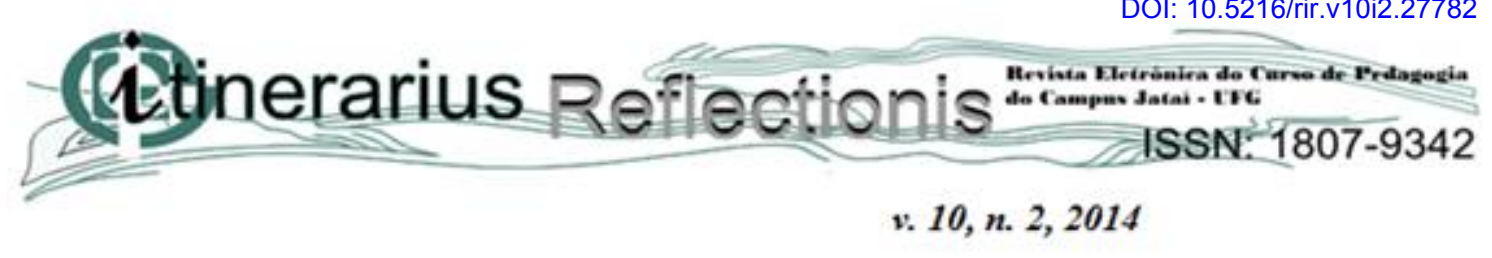

Quanto à indicação de sites apenas L1 sugere como um instrumento auxiliar para o aluno buscar outros materiais sobre o assunto estudado. Apesar do uso da internet ser constante na vida da maioria dos alunos, Carvalho e Bossolan (2009) entendem que o acesso à rede deve ser disponibilizado em diferentes locais, entre eles a escola, onde a maioria dos livros avaliados não faz referência a este instrumento, curiosamente.

Sites educacionais poderiam não somente complementar o conteúdo já ministrado, mas também ser usados pelo professor como forma diferencial de trabalho, ao utilizar o laboratório de informática, ou ainda, para incentivar e direcionar pesquisas realizadas pelos próprios alunos. Carvalho e Bossolan (2009) citam da importância dos livros didáticos se adaptarem à era da internet, pois ao estimularem e ensinarem aos alunos como trabalhar com sites educativos estarão promovendo a educação do aluno de forma diferencial e a aprendizagem significativa. Neste sentido, Carrascosa, Pérez e Valdés (2005) mencionam que as atividades em sala de aula devem fazer com que o aluno ultrapasse a simples visão contemplativa e passe a ser ativo no processo de aprendizagem. Integrar a utilização da internet no currículo de um modo significativo e incorporá-la às práticas de sala de aula, numa aprendizagem colaborativa e cooperativa, poderá fornecer um contexto autêntico em que alunos desenvolvem conhecimento, competências e valores (SILVA, 2006).

De forma semelhante, os instrumentos pedagógicos tirinhas/ história em quadrinhos e charges, apesar de atrativos para muitos estudantes, foram pouco explorados nos livros analisados, apenas L3 continha uma pequena tirinha. Esse instrumento busca ensinar, de uma forma diferente, os assuntos trabalhados promovendo a interpretação do texto e a busca da relação com o conteúdo, pois só assim farão sentido. Segundo Kamel e La Rocque (2006) as histórias em quadrinhos vêm sendo utilizadas na disciplina de língua portuguesa com resultados satisfatórios. As autoras consideram que os quadrinhos possibilitam mais um caminho de acesso nas relações de comunicação entre o sujeito e a sociedade, pois muitas são as linguagens utilizadas pela humanidade para se comunicar.

Em relação ao glossário, o mesmo esteve presente nos livros L1, L2, L5 e L7. O L1 apresentava um glossário por capítulo, onde eram definidos conceitos essenciais para 


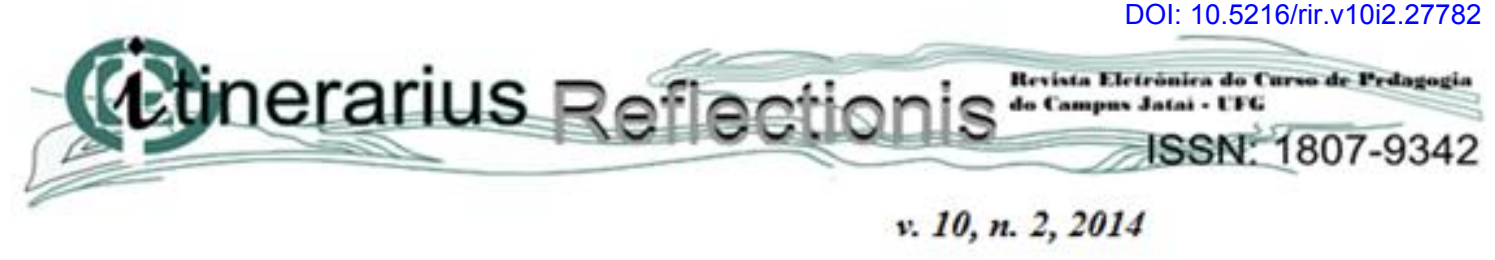

o entendimento do tema. Já nos outros livros, o glossário está presente no final do livro, sendo que o número de conceitos definidos é menor que em L1. Este instrumento pode ser facilitador no momento que define conceitos subsunçores para o entendimento do conteúdo. De acordo com Moreira (2010), em certos momentos o ensino pode ser memorístico para que os subsunçores possam ser aprendidos. Em síntese, os livros analisados reproduziram o modelo tradicional de ensino: leitura de textos e resolução de exercícios. De uma forma geral, não há incentivo à pesquisa e à educação científica e nem a preocupação em correlacionar conteúdos no campo da Geometria.

\section{Considerações finais}

Dos seis livros analisados, apenas um (L1) apresentou variedade de instrumentos auxiliares (cinco tipos das sete categorias verificadas), entre eles a indicação de sites da internet. Os livros didáticos analisados, raramente, propõem ao aluno a elaboração de hipóteses ou a necessidade de buscar novas informações fora do contexto do próprio livro, ocorrendo, então, a continuidade de um modelo de ensino que não estimula a criatividade e a busca por novos conhecimentos.

Os alunos querem que as aulas os motivem ao aprendizado, estimulem-nos à criatividade e à busca por respostas de uma forma diferente, não somente copiando respostas prontas do livro didático. Por isso, instrumentos pedagógicos diferenciais como a indicação de atividades práticas e de sites e a utilização de histórias em quadrinhos e charges são instrumentos valiosos para aproximar o aluno do conhecimento, visto que alguns destes recursos fazem parte do dia-a-dia do educando.

É importante lembrar que a visão linear, e muitas vezes alienada, da produção do conhecimento que ainda permeia o ensino, reforça a ideia de que Geometria não Euclidiana é para poucos gênios privilegiados que acertam sempre os problemas propostos. Ao largo, não contempla o aspecto de construção, os erros, os conhecimentos superados, e a própria compreensão de modelos. É a história da Matemática para gênios. Esta distorção limita a compreensão do mundo que nos cerca, das possíveis 


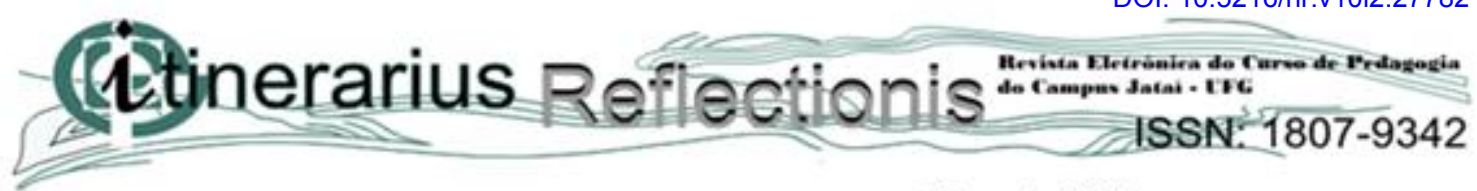 v. 10, n. 2,2014}

representações e singularidades, o que leva o indivíduo a viver em um mundo utópico e ideal.

Enquanto a linguagem cotidiana é muitas vezes responsável pela disseminação de explicações não científicas, onde o estudante apresenta significado para imagens, símbolos, modelos e representações geométricas, permitindo uma compreensão do mundo que o cerca, a prática de ensino formal de Geometria em todos os níveis privilegia a memorização de fórmulas e técnicas de resolução de problemas ainda fomentada nos alicerces da Geometria Euclidiana, ou seja, um ensino ainda centrado no plano e na exposição do professor.

Com relação aos instrumentos pedagógicos, recomendamos, que no planejamento, utilize-os de modo a facilitar o acesso ao pensamento dos estudantes, configurando um interessante aspecto a ser considerado em relação aos problemas enfrentados na prática pedagógica. No universo da sala de aula professor e estudante se relacionam o tempo todo. O professor não ensina apenas transmitindo ou reproduzindo conteúdos mesmo que com métodos testados. O fato é que esse intenso relacionamento pode favorecer a aprendizagem dos estudantes e estudar sobre como professor e estudante se aproximam na construção de um laço de confiança e respeito.

\section{REFERÊNCIAS}

ALMOULOUD, S. A. A geometria no ensino fundamental: reflexões sobre uma experiência de formação envolvendo professores e alunos. Revista Brasileira de Educação, São Paulo, n. 27, p. 94 - 108, Set /Out /Nov /Dez 2004.

ALVES, S. Geometria Não Euclidiana. São Paulo: IME-USP: material para oficina; Semana da Licenciatura, 2008.

BARRETO, M.S. Do mito da Geometria Euclidiana ao ensino das Geometrias Não Euclidianas. Vértices. Rio de Janeiro, v. 9, n.1/3, 74-81, jan. 2007.

BITTENCOURT, C.M.F. Em foco: História, produção e memória do livro didático. Educação e Pesquisa, São Paulo, v. 30, n.3, set./dez. 2004. Disponível em: <http://www.bibvirt.futuro.usp.br/textos/periodicos/educacao_e_pesquisa/vol_30_no3>. Acesso em: 3 dez. 2013. 


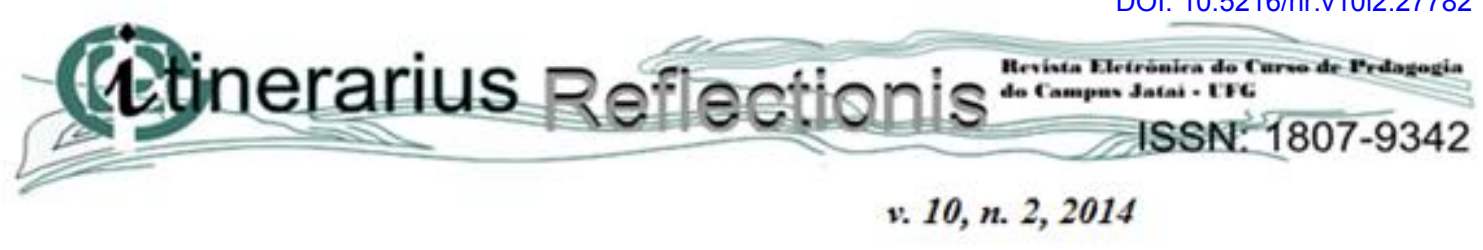

BIZZO, N. Falhas no ensino de ciências: erros nos livros didáticos ainda persistem em escolas de Minas e São Paulo. Ciência Hoje, São Paulo, v. 27, n. 159, p. 26-31, abr. 2000.

BOYER, C.B. História da Matemática. $2^{\circ}$ ed. São Paulo: Blücher, 2009.

BONGIOVANI, V. De Euclides às geometrias não euclidianas. Revista Iberoamericana de Educación Matemática. São Paulo, v.1, n. 22, p. 37-51, 2010.

BRASIL. Guia do programa nacional do livro didático. Secretaria da Educação Básica. Guia de Livros didáticos Programa Nacional do Livro Didático (PNLD). Brasília: MEC/SEF, 2007.

Secretaria de Educação Fundamental. Parâmetros curriculares nacionais: matemática. Brasília: MEC/SEF, 1998.

BRUM, W. P. Aplicação de um sequência didática para a apresentação de conceitos elementares de geometria esférica e hiperbólica no ensino médio. 205f, 2013. Dissertação de Mestrado (Universidade Regional de Blumenau - FURB).

CABARITI, E. A geometria hiperbólica na formação docente: possibilidades de uma proposta com o auxílio do cabri-géomètre. III Seminário Internacional de Pesquisa em Educação Matemática, 2006, São Paulo.

CARRASCOSA, J., PEREZ, D. e Valdés, P. Como ativar a aprendizagem significativa conceitos e teorias? Santiago: OREALC / UNESCO, 2005.

CARVALHO, M. A.; CARVALHO, A. M. C. O ensino de geometria não euclidiana na educação básica. In: XIII Conferência Interamericana de Educação Matemática, 2011, Recife.

CARVALHO, J. B.; BOSSOLAN, L. Euclides roxo e o movimento de reforma do ensino de Matemática na década de 30. Revista Brasileira de Estudos Pedagógicos. Brasília, v.81, n. 199, p.415-424, set/dez. 2009.

CEDREZ, A.J.P. Construcción, necessidad e intuición de essência em geometria. Scientia \& Studia. São Paulo, v. 7, n. 4, p. 595-617, 2012.

CURITIBA. Secretaria Municipal de Educação. Currículo básico: uma contribuição para a escola pública brasileira. Imprensa Oficial do Estado Paraná, 1988.

EVES, H. Introdução à história da Matemática. São Paulo: Unicamp, 2008.

FREIRE, P. Pedagogia da autonomia: saberes necessários à prática educativa. Rio de Janeiro: Paz e Terra, 2010. 


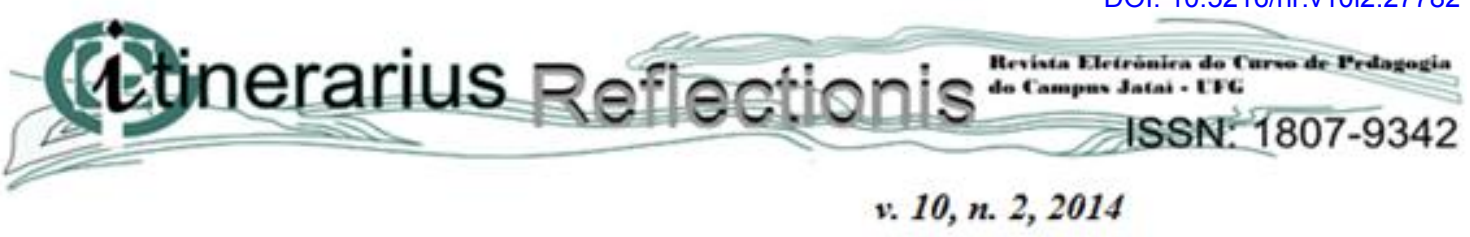

GALIAZZI, M. do C.; ROCHA, J.M.B.; SCHMITZ, L.C.; SOUZA, M.L. de; GIESTA, S.; GONÇALVES, F.P. Objetivos das atividades diferenciadas no ensino médio: a pesquisa coletiva como modo de formação de professores de matemática. Ciência \& Educação, v.7, n.2, p.249-263, 2001.

GAMBARINI, C.; BASTOS, F. A utilização do texto escrito por professores e alunos nas aulas de ciências naturais e exatas. In: NARDI, R.; ALMEIDA, M. J. P. M. (Orgs.). Analogias, leituras e modelos no ensino da ciência: a sala de aula em estudo. São Paulo: Escrituras, 2006. p. 93-115.

KALEFF, A.M. Desenvolvimento de Atividades Introdutórias ao Estudo das Geometrias não Euclidianas: Atividades Interdisciplinares para Sala de Aula e Museus Interativos. In: Congresso Brasileiro de Extensão Universitária, n. 2, 2004. Belo Horizonte.

KAMEL, C.; LA ROCQUE, L. As histórias em quadrinhos como linguagem fomentadora de reflexões - uma análise de coleções de livros didáticos de ciências naturais do ensino fundamental. Revista Brasileira de Pesquisa em Educação em Ciências. $\quad$ v. $6, \quad$ n.3, 2006. Disponível em: <http://www.fae.ufmg.br/abrapec/revistas/v6n3a3.pdf>. Acesso: 15 de dez. 2013.

LEIVAS, J.C.P. Educação geométrica: reflexões sobre ensino e aprendizagem em geometria. Revista SBEM-RS, Porto Alegre, no. 13, v.1, p. 9-16, 2012.

MARTOS, Z.G. Geometrias não euclidianas: uma proposta metodológica para o ensino de Geometria no Ensino Fundamental. Rio Claro, 2002. 143f. Dissertação (Mestrado em Educação Matemática) - Instituto de Geociências e Ciências exatas, Universidade Estadual Paulista.

MLODINOW, L. A janela de Euclides: a história da geometria, das linhas paralelas ao hiperespaço. São Paulo: Geração, 2010.

MOREIRA, M. A. Mapas conceituais e aprendizagem significativa. São Paulo: Centauro, 2010.

SÃO PAULO. Secretaria de Educação. Coordenadoria de Estudos e Normas Pedagógicas. Proposta curricular para o ensino de Matemática do $1 .^{\circ}$ grau. $4^{\mathrm{a}}$. ed. São Paulo: SE/CENP, 1991.

SILVA, C. P. B. Atualizando pedagogias no campo da matemática para o ensino médio: um estudo sobre a Revista Atualidades Pedagógicas (1950-1962). Dissertação de Mestrado, PUC-SP, 2001.

SILVA, A.F.A. Ensino e aprendizagem de Ciências nas séries iniciais: concepções de um grupo de professoras em formação. Dissertação de Mestrado, Programa de Pós- 


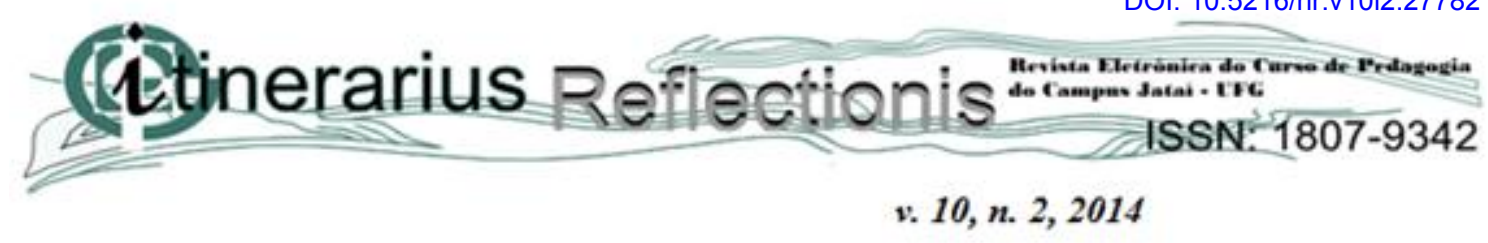

Graduação Interunidades em Ensino de Ciências, Universidade de São Paulo, São Paulo, SP., 2006.

SOUTO, A. Análise de livros didáticos de matemática: uma investigação. Trama. v. 4, n. 7, p. 45-54, 2008.

STRUIK, D.J. História Concisa das Matemáticas. São Paulo: Gradiva, 2010.

TAMBARA, E. Trajetórias e natureza do livro didático nas escolas de ensino primário no século XIX no Brasil. In: História da Educação. (FAE/Ufpel), Volume 6, Número 11, p. 5 - 24, Pelotas, Abril 2002.

TRIVELATO, S. L. F. Ensino de Geometria: uma perspectiva. São Paulo: Faculdade de Educação, 2008.

VALENTE, W. R. Controvérsias sobre Educação Matemática no Brasil: Malba Tahan versus Jacomo Stávale. Cadernos de Pesquisa, n. 120, p. 151-167. Novembro de 2003.

VASCONCELOS, S. D.; SOUTO, E. O livro didático de ciências exatas no ensino fundamental - proposta de critérios para análise de conteúdo. Ciência \& Educação. v. 9, n.1, p. 93-104, 2003.

VITRAC, B. A invenção da geometria. In Scientific American-História: n.3. São Paulo: Ediouro, 2006.

VOGELMANN, E.P. A arte de ensinar e construir o conhecimento. São Paulo: Saraiva, 2011. 